\title{
Evaluation of the urban regulations by three-dimensional modelling: the district of Providencia in Santiago, Chile
}

\author{
D. Wurman \& H. Torrent \\ Pontificia Universidad Católica de Chile
}

\begin{abstract}
This paper presents a methodological approach for the evaluation of the urban regulation and its application to a real case in the district of Providencia in Santiago, Chile.

As opposed to the traditional textual-discursive and two-dimensional elaboration of the urban regulation, the digital instruments allow an immediate verification of the generated volumes, as well as the alternatives of variation and contradictions that it contains. The three-dimensional modelling is used as an instrument capable of showing efficiently the immediate verification of the instruments proposed within the urban changes and dynamics. It also offers the possibility of generating the norm itself from a sequence of procedures that gathers the dynamics of transformation and models them like a series of possible situations. Considering that all urban norms have a pretension and formal result, the methodological approach proposed starts from the shape and the dynamics for the creation of the norm.

This paper will show particularly the three-dimensional model of the norms on the existing property layout, and the volumes that it proposes in relation to the property division and its variation (property fusion, highly frequent condition in the cities of the developing countries), and evaluates its effects according to the site coverage, plot area ratio, and setback. The three-dimensional modelling of the volumes generated by the regulation was made using the software AutoCad, $3 \mathrm{dStudio}$, FormZ, Excel, and its linkings.

Keywords: urban regulation, three-dimensional modelling, urban dynamics, urban transformation, visual analysis, norm, normative.
\end{abstract}




\section{Introduction}

The urban norms tend to regulate the urban form, through the establishment of an ideal form, by means of a series of clear, precise and stable parameters. Nevertheless, the development of the urban form is being determined by patterns apparently disorganized and impelled by private managements with diverse rules. The form conception habitually contained within the norms supposes a stabilized urban dynamic.

In countries with accelerated economical growth, the maximum volume allowed by the legal norm is rapidly transferred to reality, reason why, the threedimensional parameters of the laws suggest a form of city.

As opposed to the traditional textual-discursive and two-dimensional elaboration of the urban regulation, the digital instruments for the formal generation, allows an immediate verification of the generated volumes, as well as the alternatives of variation, contradictions and possibilities that the same regulation contains.

The three-dimensional modelling is used as an instrument capable of showing the conditions of the regulations against the changes and urban dynamics, and permits rapidly and efficiently the immediate verification of the instruments proposed within those dynamics; for example, the formal implications of the variations of the plot area ratios affected by the property fusion. But it also offers the possibility of generating the norm itself from a sequence of possible procedures that gathers the dynamics of transformation and models them like a series of possible situations. Considering that all urban norms have an implied purpose and formal result, the methodological approach proposed starts from the shape and the dynamics for the creation of the norm.

This paper presents a methodological approach for the evaluation of the urban regulation and its application to a real case in the district of Providencia in Santiago, Chile. The urban form of Providencia comes from the model of garden city and the principal normative instruments are: the "setback" (rasante), the "front yard" (antejardín) and the "plot area ratio" (constructibilidad) [1]. For some time now, it has been arranged to promote the fusion of properties with an extra $30 \%$ of the plot area ratio, maintaining the restriction of the "site coverage" (ocupación de suelo) to $40 \%$ [2].

In this paper, the three-dimensional modelling of the existing regulations applied to an existing block is exposed.

The regulation set of the district of Providencia was analyzed using mathematical models to discover the method of formulation and implications of the values that are managed within the district.

\section{Three-dimensional modelling of Providencia's regulation}

The visual analysis of the ordinance, consists in three-dimensionalized the normative variables that define the built-up form; especially through its limiting to the maximum building volume allowed in every property. 
A block that was in a zone of possible imminent transformation was chosen. On this block, successive hypotheses were applied taking into account the incentive for the fusion of properties, which allows an increase of the plot area ratio and therefore greater success in the economic aspects of the real estate operation that it assumes. The supposed situation of unions between neighbouring properties mainly inclined to be fused was considered (fig. 1).

In order to spatially visualize the norm proposal, six successive modelling and analyses operations were carried out using Autocad, FormZ, 3d Studio and Excel.

\subsection{Operation_01}

Polygons were defined for each possible property fusion according to the demarcations between the grouped properties and the axes of the roadways that they face. From them, following the setback a pyramid is raised with an inclination of $70^{\circ}$, as the norm establishes it for Santiago (fig. 2).
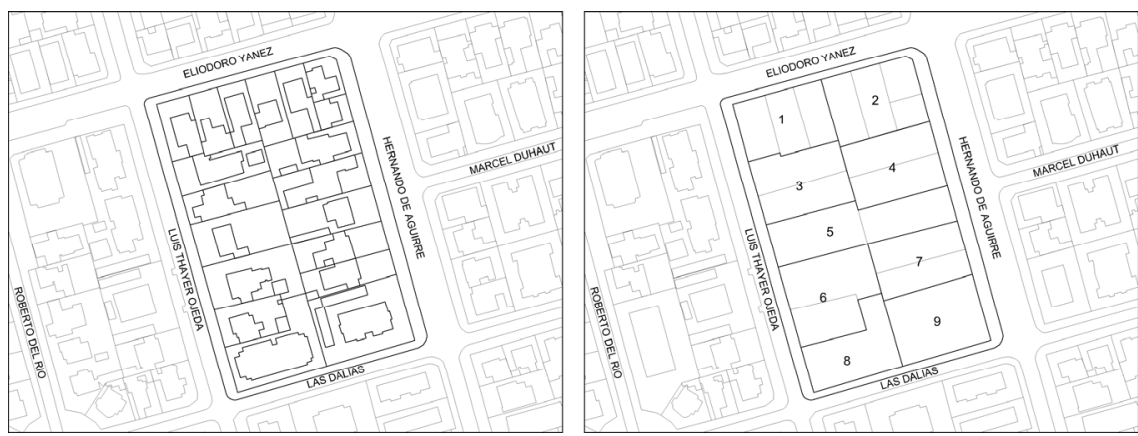

Figure 1: Chosen block (left) and possible property fusion (right).

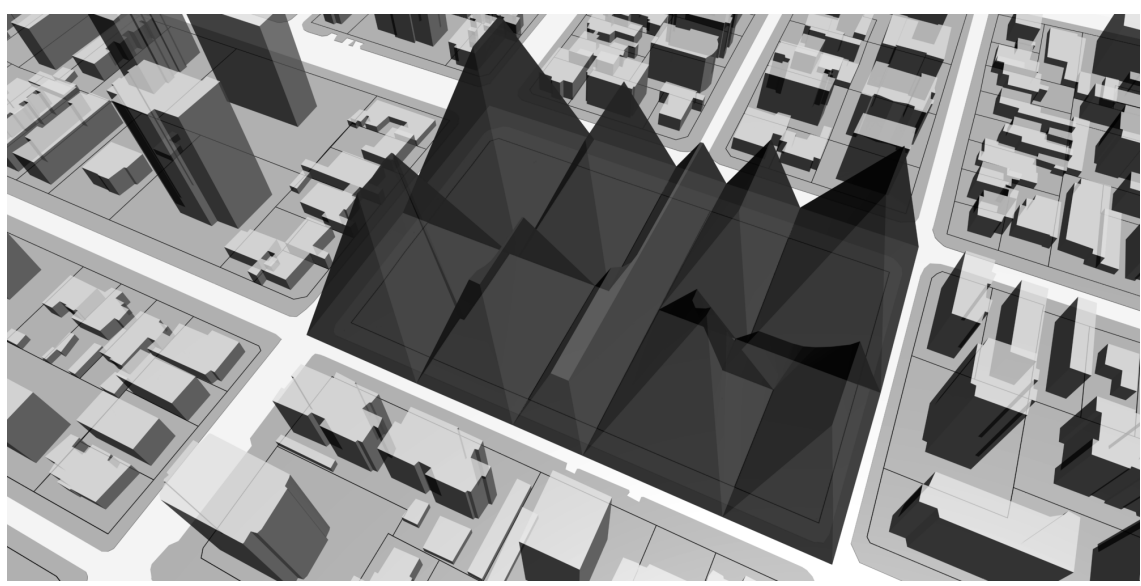

Figure 2: Volumes defined by the setback (Rasante) for each property fusion. 
The setback (rasante) is an imaginary straight line that, in a certain angle, defines the theoretic surrounding in which a construction project can be developed. This angle in Santiago is $70^{\circ}$. The Rasante will rise in all the points that form the border with other property and in the midpoint between official lines of the public space that faces the property.

\subsection{Operation_02}

The Antejardin (front yard) is the area free of construction between the official line and the line of building. To translate this to volumetric representable conditions, three volumes were formed with the options of the "extrude" command in AutoCad, and then joined one over the other as shown in figure 3.

a) The first volume that rises from the polyline limited by the boundaries with other properties and the retreated line in $5 \mathrm{~m}(16,40 \mathrm{ft})$ from the sides that face a street. This polyline is extruded in $90^{\circ}, 16 \mathrm{~m}(53,49 \mathrm{ft})$ high.

b) The second volume: - sort of a truncated pyramid - extruded $14 \mathrm{~m} \mathrm{(45,93}$ $\mathrm{ft})$, with an inclination of $73,3^{\circ}$, or an "angle of taper for extrusion" of $16,7^{\circ}\left(90^{\circ}\right.$ $\left.-73,3^{\circ}\right)$, resulted from the $30 \mathrm{~cm}(11,81 \mathrm{ft})$ retreat per every meter gained in height.

c) The third volume has a pyramidal form. It is raised from the polyline limited by the "plateau" of the previous volume, extruded with an inclination of $59^{\circ}$ until his faces join, resultant of the $60 \mathrm{~cm}(23,62$ in) retreat per every meter gained in height.

\subsection{Operation_03}

A final volume is constituted using AutoCad's "intersection" tool. This volume is defined like the intersection of the space limits of the Rasante and the Antejardin (fig. 4). Thus, the conditions that govern each project individually are graphically revealed on the scale of the block.

\subsection{Operation 04}

On the obtained volumes, the tool "contours" of the program FormZ was used. This tool makes consecutive sections of a volume at a defined distance. In this case, horizontal sections every $2,5 \mathrm{~m}(8,20 \mathrm{ft})$, simulating the height of a housing building (fig. 5).

The result is a series of possible outlines or silhouettes of repeatable floors with the intention of creating volumes that avoid the inclined planes of the resulting project, but staying within the volumetric margins limited by the norms.

\subsection{Operation_05}

With the data of the ratios and the area of each of the property fusions, a table was generated in the program Excel that shows the maximum building area allowed in each group, considering the increase of $30 \%$ of the plot area ratio by property fusion, resulting a plot area ratio of 2,08 (table 1). 


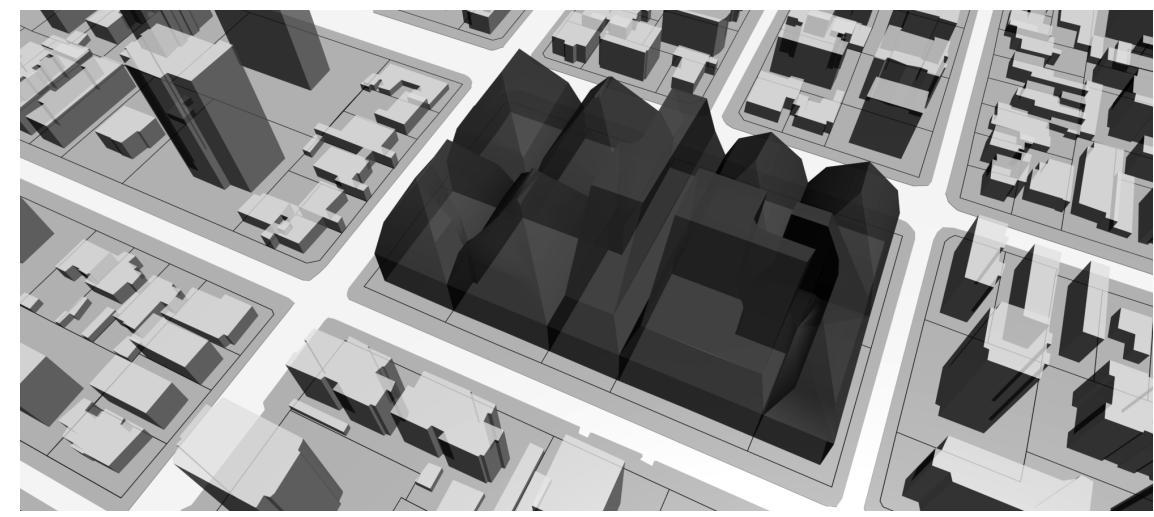

Figure 3: Volumes defined by the front yard regulation (Antejardín) for each property fusion.

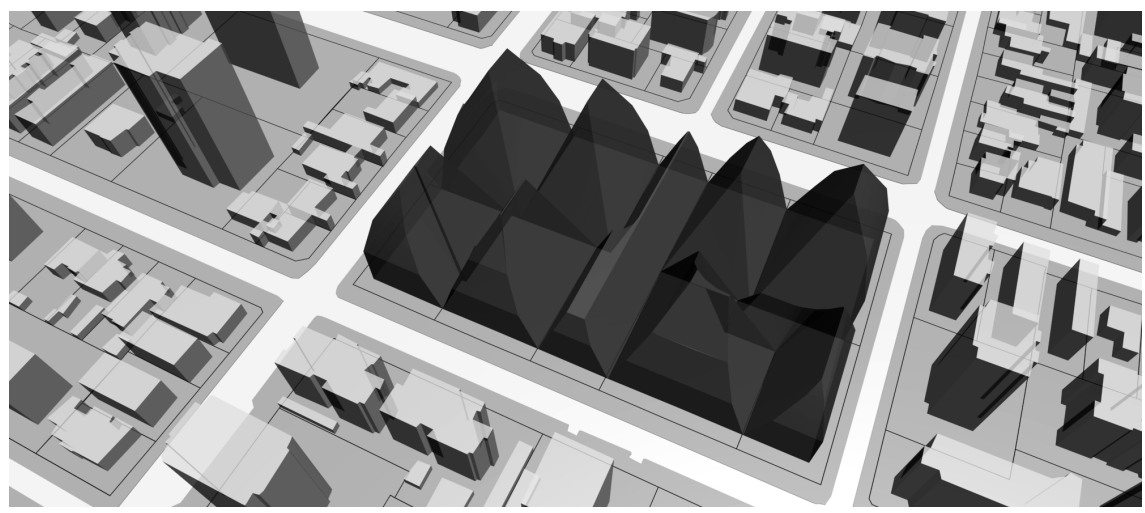

Figure 4: Volumes defined by the intersection of the space limits of the Rasante and the Antejardin.

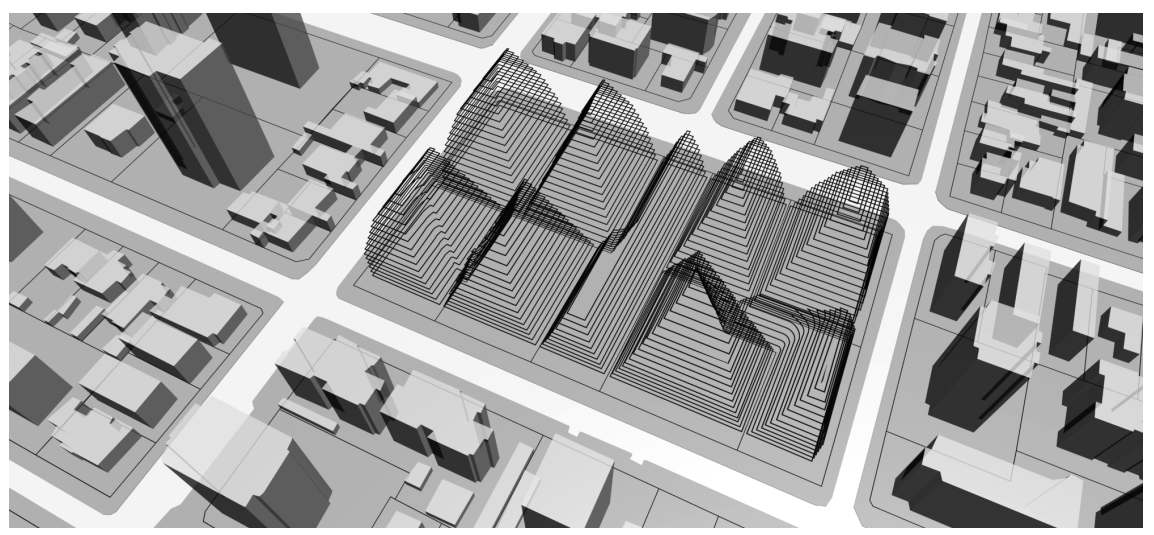

Figure 5: Possible silhouettes of the final volumes made with the FormZ command "contours" every $2,5 \mathrm{~m}(8,20 \mathrm{ft})$.

WIT Transactions on The Built Environment, Vol 90, (C) 2006 WIT Press www.witpress.com, ISSN 1743-3509 (on-line) 
The resulting area was divided into "floors" (numbers in bold), and were compared with the areas of the "contours" (numbers in italic), looking for the pair with smaller difference (marked in grey).

It is very improbable that both numbers match, so a "margin of inaccuracy" of until a $25 \%$ of the area of "contour" over the corresponding "floor" was used.

\subsection{Operation_06}

The numbers marked in grey in table 1 would be the area of the "contour" to be extruded to shape the volume that represents a building in the model.

Figure 6 is a graphic response that visualizes the spatial consequence that is being stimulated by increasing the plot area ratio by property fusion.

Table 1: $\quad$ Comparative table of the areas of the contours (numbers in italic) and the distribution of the maximum building area in floors (numbers in bold).

\begin{tabular}{|l|r|r|r|r|r|r|r|r|r|}
\hline Property fusion & 1 & 2 & 3 & 4 & 5 & 6 & 7 & 8 & 9 \\
\hline $\begin{array}{l}\text { Property fusion } \\
\text { area }\left(\mathrm{m}^{2}\right)\end{array}$ & 1645,9 & 1881,9 & 1701,7 & 1771,3 & 2156,9 & 1986,6 & 1528,9 & 1458,9 & 1828,1 \\
\hline Property fusion & & & & & & & & & \\
area $x 2,08\left(\mathrm{~m}^{2}\right)$ & 3423,5 & 3914,4 & 3539,5 & 3684,3 & 4486,4 & 4132,1 & 3180,1 & 3034,5 & 3802,4 \\
\hline 8 floors & $\mathbf{4 2 7 , 9}$ & $\mathbf{4 8 9 , 3}$ & $\mathbf{4 4 2 , 4}$ & $\mathbf{4 6 0 , 5}$ & $\mathbf{5 6 0 , 8}$ & $\mathbf{5 1 6 , 5}$ & $\mathbf{3 9 7 , 5}$ & $\mathbf{3 7 9 , 3}$ & $\mathbf{4 7 5 , 3}$ \\
& 709,6 & 884,6 & 705,2 & 762,7 & 592,5 & 871,3 & 586,2 & 414,5 & 843,7 \\
\hline 9 floors & $\mathbf{3 8 0 , 4}$ & $\mathbf{4 3 4 , 9}$ & $\mathbf{3 9 3 , 3}$ & $\mathbf{4 0 9 , 4}$ & $\mathbf{4 9 8 , 5}$ & $\mathbf{4 5 9 , 1}$ & $\mathbf{3 5 3 , 3}$ & $\mathbf{3 3 7 , 2}$ & $\mathbf{4 2 2 , 5}$ \\
& 619,5 & 786,5 & 608,8 & $\mathbf{6 6 4 , 7}$ & 423,7 & 761,8 & 496,4 & 335,3 & 747,8 \\
\hline 10 floors & $\mathbf{3 4 2 , 3}$ & $\mathbf{3 9 1 , 4}$ & $\mathbf{3 5 4 , 0}$ & $\mathbf{3 6 8 , 4}$ & $\mathbf{4 4 8 , 6}$ & $\mathbf{4 1 3 , 2}$ & $\mathbf{3 1 8 , 0}$ & $\mathbf{3 0 3 , 5}$ & $\mathbf{3 8 0 , 2}$ \\
& 535,0 & 693,9 & 518,5 & 572,8 & 260,5 & 658,7 & 412,6 & 263,1 & 657,3 \\
\hline 11 floors & $\mathbf{3 1 1 , 2}$ & $\mathbf{3 5 5 , 9}$ & $\mathbf{3 2 1 , 8}$ & $\mathbf{3 3 4 , 9}$ & $\mathbf{4 0 7 , 9}$ & $\mathbf{3 7 5 , 6}$ & $\mathbf{2 8 9 , 1}$ & $\mathbf{2 7 5 , 9}$ & $\mathbf{3 4 5 , 7}$ \\
& 456,0 & 606,8 & 434,3 & 486,9 & & 562,0 & 334,9 & 197,1 & 572,4 \\
\hline 12 floors & $\mathbf{2 8 5 , 3}$ & $\mathbf{3 2 6 , 2}$ & $\mathbf{2 9 5 , 0}$ & $\mathbf{3 0 7 , 0}$ & $\mathbf{3 7 3 , 9}$ & $\mathbf{3 4 4 , 3}$ & $\mathbf{2 6 5 , 0}$ & $\mathbf{2 5 2 , 9}$ & $\mathbf{3 1 6 , 9}$ \\
& 382,5 & 525,2 & 356,2 & 407,0 & & 471,7 & 263,2 & 136,8 & 493,0 \\
\hline 13 floors & $\mathbf{2 6 3 , 3}$ & $\mathbf{3 0 1 , 1}$ & $\mathbf{2 7 2 , 3}$ & $\mathbf{2 8 3 , 4}$ & $\mathbf{3 4 5 , 1}$ & $\mathbf{3 1 7 , 9}$ & $\mathbf{2 4 4 , 6}$ & $\mathbf{2 3 3 , 4}$ & $\mathbf{2 9 2 , 5}$ \\
& 286,6 & 416,5 & 275,3 & 324,2 & & 372,1 & 192,5 & 59,4 & 387,5 \\
\hline 14 floors & $\mathbf{2 4 4 , 5}$ & $\mathbf{2 7 9 , 6}$ & $\mathbf{2 5 2 , 8}$ & $\mathbf{2 6 3 , 2}$ & $\mathbf{3 2 0 , 5}$ & $\mathbf{2 9 5 , 2}$ & $\mathbf{2 2 7 , 2}$ & $\mathbf{2 1 6 , 8}$ & $\mathbf{2 7 1 , 6}$ \\
& 202,5 & 319,3 & 203,4 & 250,2 & & 281,6 & 130,6 & & 293,6 \\
\hline
\end{tabular}

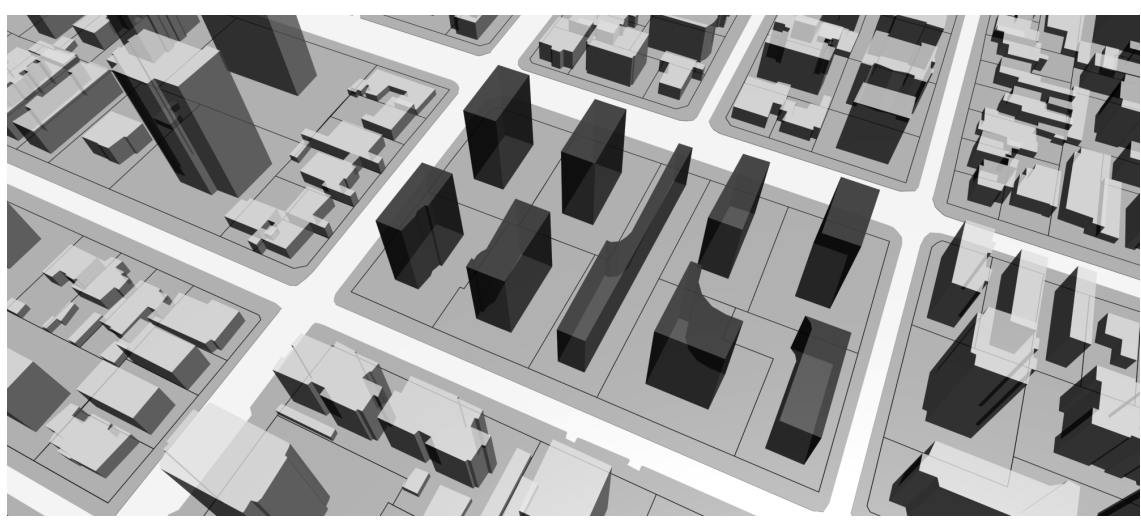

Figure 6: Graphic response of the regulation of Providencia. 


\section{Analysis of the combination of normative variables}

Behind every norm there is a city model. The digital technology allows, in an efficient way, to recognize this model, but also allows, in the way of evaluating its possible effects that are not clear enough in the application of a traditional set of instruments that has had only partial, graphic or written formulations.

With the interest of analyzing the combination of three variables that delimit the volumes, plot area ratio, site coverage and setback (rasante), different software were used - Matlab, Excel and AutoCad. For this study they were considered the same numbers proposed in the previous exercise.

\subsection{Plot area ratio (constructibilidad) and site coverage (ocupación de suelo)}

The constructibilidad (plot area ratio) is the number that multiplied by the total surface of the property, equals the maximum square meters allowed to build.

The ocupación de suelo (site coverage) is the percentage of the surface of the property that is allowed to be built on the ground level.

Figure 7 shows the volumes that the combinations of these variables create.

For example, a plot area ratio of 2,08 and a site coverage of $40 \%$, being coefficients of the same number - the surface of the property - the number of floors to construct is obtained dividing one in the other. That is, $2,08 \div 0,4=5,2$ floors (without considering $20 \%$ of public use).

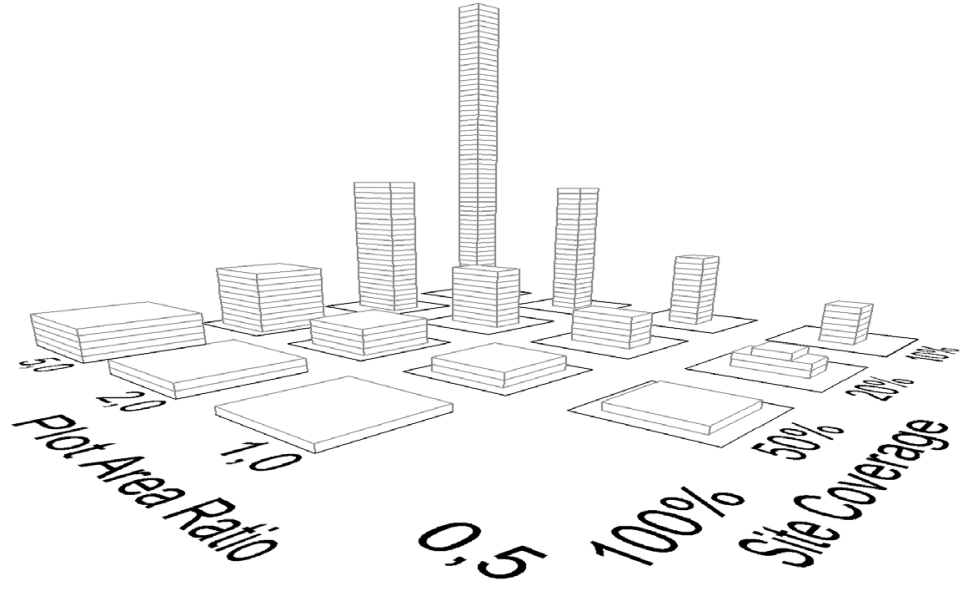

Figure 7: Diagram of the combination of the plot area ratio and the site coverage.

\subsection{Setback (rasante) and plot area ratio (constructibilidad), with respect to a fixed site coverage (ocupación de suelo)}

In order to define the maximum building volume that results from the combination of the rasante and the constructibilidad, it was defined the variable " $y$ " as the distance to the border (fig. 8), and the constants "a" and "b" as the 
width and length of the property, respectively and they vary between 9 and $60 \mathrm{~m}$ to cover the totality of existing sites in the district.

Thus, and considering an ocupación de suelo of $40 \%$, the following equation appeared:

$$
(a-2 y)(b-y)=0.4 a b
$$

With the results of the equation (1) a matrix - in Excel - was generated that shows the uniform distancing towards each edge, in meters, of an area of a $40 \%$ of the property. From this first matrix, was generated a second matrix, that shows at what height this area intersect with the rasante of $70^{\circ}$.

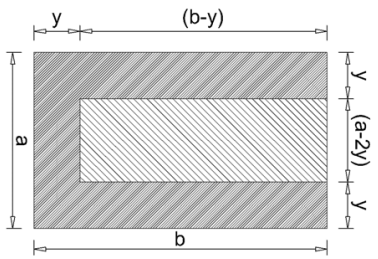

Figure 8: Explanatory diagram of the proportions in equation (1).
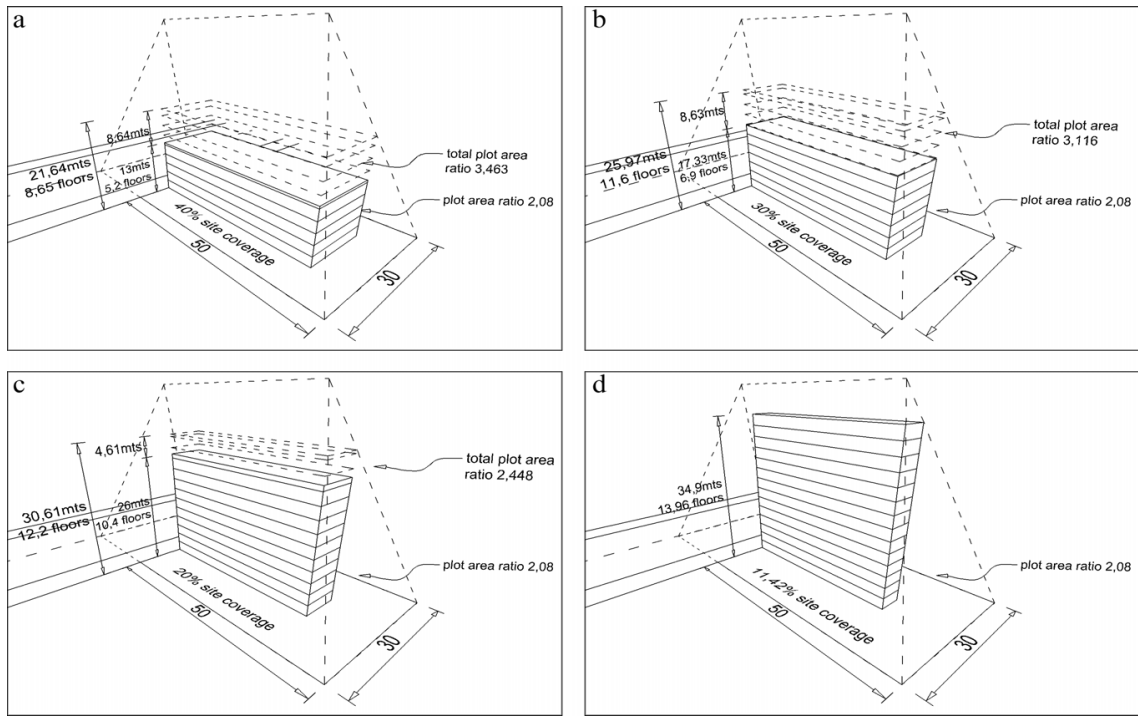

Figure 9: Diagram of the volumes allowed by a site coverage of (a) $40 \%$, (b) $30 \%$, (c) $20 \%$ and (d) $11,42 \%$ in an example property of $30 \times 50 \mathrm{~m}$.

A third matrix was generated considering floors of 2,5 $\mathrm{m}$ high. This shows the constructibilidad of each one of these volumes, and reveals that with a site 
coverage of $40 \%$, there are very few properties that have a constructibilidad of 2,08 , and besides, given their proportions, either they do not exist in the district or they can't be formed by fusion of properties. It also shows that the constructibilidad that would fulfil this conditions, is much more than 2,08 , but in no case it would exceeded 9 floors of height (fig. 9a). The same matrices were elaborated for site coverages of $30 \%$ and $20 \%$, obtaining results that show the current alternatives of construction in the district, higher buildings and less site coverage (figs. 9b, 9c and 9d).

\subsection{Ocupación de suelo and rasante, with respect to a fixed constructibilidad}

This problem was solved and illustrated using the software Matlab as shown.

"a" and "b" are the values in meters of the width and length of the property respectively, and " $p$ " is the site coverage measured in percentage (fig. 10).

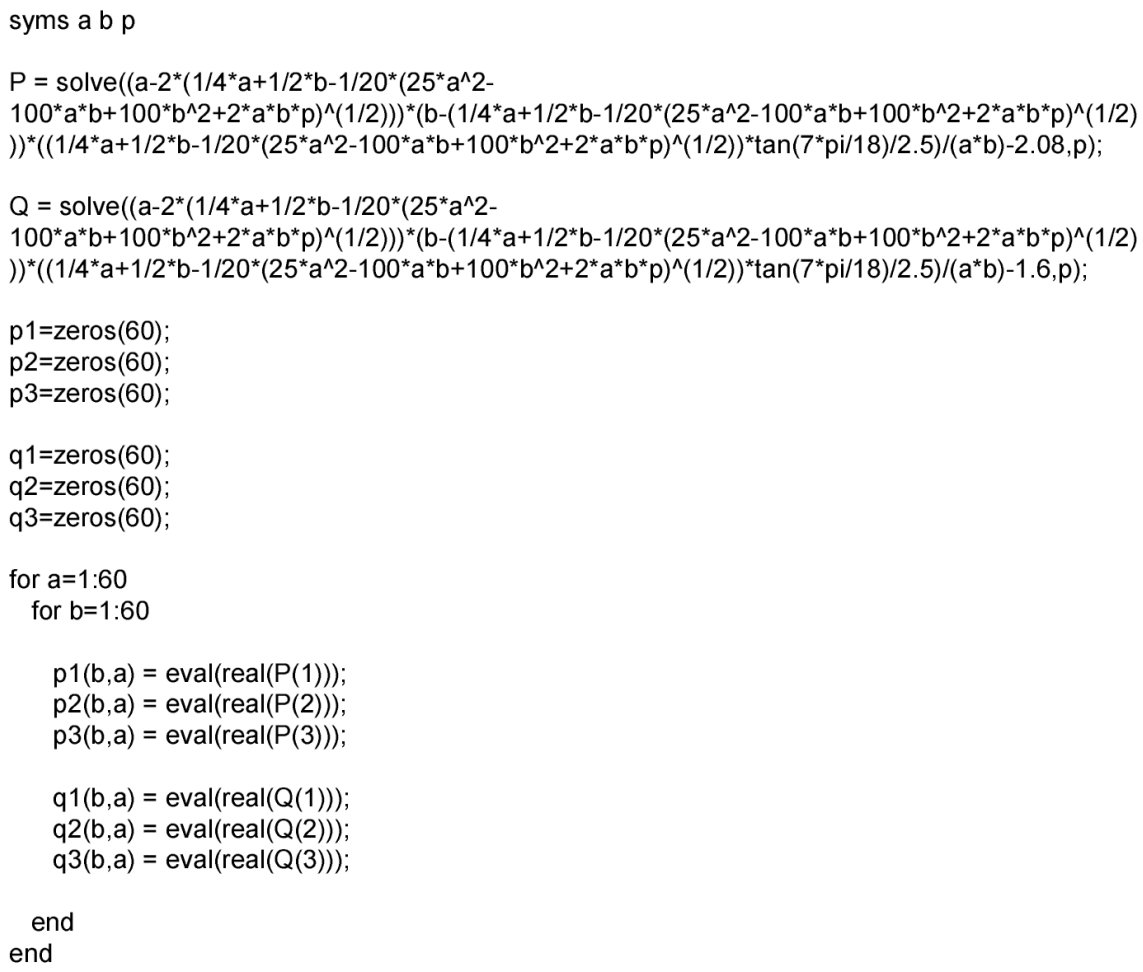

Figure 10: Input of the equations in Matlab language for it to solve.

Each equation ("P" and "Q") returns three matrices (p1, p2, p3, and q1, q2, q3) like results for each property $(a, b)$. These matrices show the percentage of coverage, that extruded until the height which they touch the rasante and divided 
in floors of $2,5 \mathrm{~m}$ high, are equivalent in constructibilidad to 2,08 and 1,6, even if its not an exact number of floors. This is illustrated in figure 11 .

This shows that does not exist only one coverage that responds to the demanded constructibilidad, but three possible coverages to reach a constructibilidad of 2,08 and 1,6 in every property, but that in the properties that might result from a property fusion, $40 \%$ of coverage is not a restrictive value.
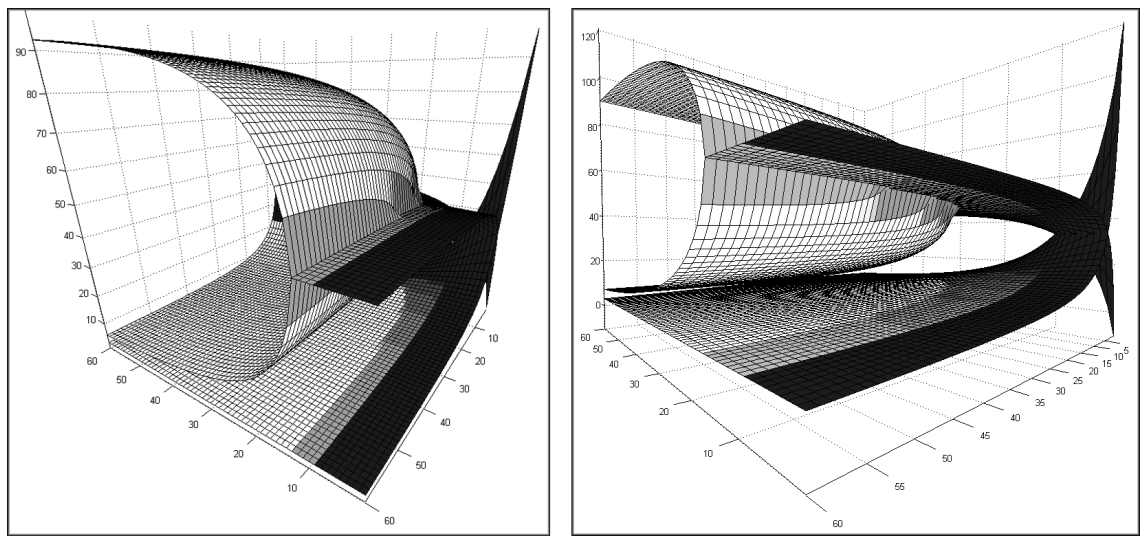

Figure 11: Three-dimensional graphics generated in Matlab, which shows three possible site coverages (in percentage) that a constructibilidad of 1,6 (left) and 2,08 (right) would allow for every property. The grey zone represents the existing properties in the district, and the white zone the possible sites formed by fusion of properties. The properties represented by the black zone do not exist, but they were included in the graph for his continuity.

\section{Final remark}

The modelling of the regulation allows verifying that the possibilities are grater than the initially foreseen by the norms. For example for the point " 3.2 Distancing \& plot area ratio, respect a fixed site coverage", it verifies that when $40 \%$ of site coverage is restrictive, the constructibilidad should be much more, and the point "3.3 Ocupación de suelo \& rasante, respect a fixed constructibilidad" verifies that a site coverage of $40 \%$ is not always restrictive.

The three-dimensional modelling allows in this case a fast and effective visualization of the problem. It might have been part of the formulation of the norm if it had been elaborated through these means.

Using the three-dimensional modelling as an investigation tool allows identifying the city model beneath a regulation. This way, it is possible to evaluate urban and architecturally as city proposal.

This system raises a method possible to be used in the generation and evaluation of the regulations. It also allows managing the problem of the obsoleteness and lack of dynamism of these. 
This way, the urban effects of a norm can be evaluated spatially, before being validated, or, in an inverse way, create a norm stain from the form.

\section{References}

[1] Ministerio de Vivienda y Urbanismo (Housing and Urbanism Ministry), Ordenanza General de Urbanismo y Construcciones (General Ordinance of Urbanism and Construction). Santiago, Chile, 2006.

[2] Ilustre Municipalidad de Providencia (Municipality of Providencia), Ordenanza Local de Edificación y Construcción para la Comuna de Providencia (Local Ordinance of Edification and Construction for the District of Providencia), Chile, 2001. 